\title{
How to get better at flatter designs: considerations for shaping and leading organizations with less hierarchy
}

\author{
Markus Reitzig ${ }^{1}$ (i)
}

Received: 19 October 2021 / Accepted: 15 January 2022 / Published online: 27 January 2022

(c) The Author(s) 2022

\begin{abstract}
Working with fewer hierarchical layers than has been the case traditionally is often considered critical for firms to become more innovative, speedier, and retain and attract gifted personnel in today's world. The upside appears great, but so do the associated risks of creating a dysfunctional organization. I propose that systematically thinking through a series of classic organization design questions to shape a custom-tailored design is promising when delayering grown hierarchies or growing start-ups to remain flat. More promising than adopting any one fashionable management approach wholesale.
\end{abstract}

Keywords Organizational structure $\cdot$ Corporate hierarchy $\cdot$ Flat structure $\cdot$ Delayering $\cdot$ Decentralizing $\cdot$ Autonomy

\section{Introduction}

Traditional hierarchies have fallen from grace in the perception of many scholars and practitioners of organization design. At least one can't help thinking so, when inspecting the plethora of recent and not so recent approaches that promote "teams-based" organizing as an alternative to bureaucratic management. From "a" as in "agile" to "z" as in "zi zhu jing ying ti", the list of solutions developed by practitioners has been growing steadily over the past decades, and with it, so it seems, the writings by management scholars who portray selected vanguard organizations. And yet, the thinking does not seem to gain as much traction as one might expect given the attention it receives in the management literature, at least when we look at the formal elements of organizational structure. In 2017, about half of the US labor force still worked in organizations employing more than 500 people (US Census Bureau 2021), and while hierarchies seem to have become somewhat flatter over time (Rajan and Wulf 2006), it would still appear that an 800 person company would easily have four layers of management or more, depending on its industry (see, e.g., Smeets and Warzynski 2008). I propose that three mutually non-exclusive explanations may account for this finding.

Markus Reitzig

Markus.Reitzig@univie.ac.at

1 Strategic Management Subject Area, University of Vienna, Oskar-Morgenstern-Platz 1, A-1090 Vienna, Austria
First, hierarchical structures may not be that bad after all, and they may come in handy when scaling teams-based work becomes difficult. Second, maybe it just takes longer for us to witness managerial attempts of moving to flatter structures empirically, because corporations are changing slowly. ${ }^{1}$ Third, perhaps managers have already tried to implement flatter structures, but abandoned these endeavors when encountering problems. This article argues that the last problem is an important one and will prevail unless decision-makers start to think about designing flat structures systematically: what it means to operate a flat structure, what managers can delegate, why which employees would thrive in such high delegation regimes, which boundary conditions to set for effective and efficient self-organization, and what (not) to use a flat structure for.

\section{What does it mean to operate a "flatter" structure?}

Company hierarchies are stacks of authoritative relationships. All else remaining constant, notably the number of employees, removing a layer in a grown hierarchy means that the span of control for each remaining manager increases. Unless management changes its way of working, this creates an impasse, because the workload of the remaining executives increases non-linearly with each person directly reporting to them. To avoid ending up in this scenario management must, therefore, delegate more work to their employees than

\footnotetext{
${ }^{1}$ It is conceivable that informal structures move towards being more egalitarian faster than formal structures would.
} 
they would in an alternative scenario. These alterations to the ways in which decision-makers and employees work in such a flatter structure - as compared to a traditional hierarchy-bring about challenges for all members of the organization. Similarly, start-ups, when growing their ventures, often reach a point when the span of control for the founding team increases beyond what seems like a manageable level. For these companies to retain their flat structure and not to move to a hierarchical one is equally demanding.

All too often, however, the success stories we hear about such transformations or flat growth processes create the impression as though operating with little or no hierarchy was easy. However, while it is true that companies such as T-Systems (Germany) or Reaktor (Finnland) provide examples of how this can work, there are also plenty of instances of comparable firms operating in the same or similar industries, where such high delegation regimes did not work out. Take Wistia (US) or Treehouse (US) as cases in point, where management abandoned their flat structures and returned to, or introduced, steeper hierarchies eventually (For details on these cases see Reitzig 2022, ch. 1).

\section{What managers can effectively and efficiently delegate}

If one were to analyze what organizations known to informally decentralize many decisions to their employees do well, one would - amongst other things-arrive at the insight that their high delegation regimes save their management time. Time which executives can spend on other pressing problems they must not delegate. Many of these companies-e.g., Atos (France), Buurtzorg (Netherlands), W.L. Gore Associates (US), Patagonia (US), Smarkets (UK), and Squarespace (US) - are being explicit about this (Reitzig 2022, ch. 2). Interestingly, however, when taking a closer look, these time savings would stem from delegating decisions in very different domains of managerial work. As my colleagues Phanish Puranam, Oliver Alexy, and I argued several years back, managers, when devising organizational designs, would traditionally have to attend to four problems (Puranam et al. 2014), namely, to (1) divide tasks (determine what needs to be done), (2) allocate tasks (determine who does what), (3) distribute rewards (determine who gets what), and (4) provide information (determine who needs to know what). In addition, because such designs would never be able to factor in unforeseen problems, managers would also have to engage in managing exceptions and conflicts along the way. Importantly, so the detailed company case analysis shows, firms do not have to delegate decision-making across all of these $4(+1)$ domains as radically as video game producer Valve to create some breathing room for their CEO without him having to draw on mid-level managers (Valve 2012). In fact, some companies would primarily allow for decentral information exchange (Burkus 2016; Oettl et al. 2018), others would permit their employees to determine their own compensation (Patagonia-Chouinard 2016; Smarkets-Smarkets 2016), and yet others would foster self-selection into tasks (W.L. Gore Associates-Kelly n.d.). It thus appears that when management "let go" of their decision-making power, where they have chosen to delegate in the first place, the potential of the flat structure starts to emerge. Whether that potential manifests itself in increased corporate performance, depends on a series of other determinants, however; one of them being how employees embrace the new autonomy they are being given to take decisions.

\section{Why and which employees would thrive in high delegation regimes?}

High delegation regimes eventually put an extra burden on employees. Inevitably, with their receiving - at least partial-autonomy to take their own decisions in addition to carrying out their extant tasks, they will face a higher workload than in a comparable traditional organization. To make work in a flat company a viable proposition from a worker's perspective, autonomy must thus unleash extra effort on the part of the people in the company. Both science and anecdotal evidence suggests that this can be the case. At least four different streams of literature-self-determination theory (Ryan and Deci 2000), job design (see Hackman and Oldham 1976 and the works that built on them), organizational commitment (Mathieu and Zajac 1990), general management (see, e.g., Ivancevich and Donnelly 1975)—suggest that autonomy can trigger five different psychological mechanisms that lead employees to exert more effort: self-actualization (Morrison 1994; Hofmann et al. 2003), perceived control (Spector 1986), attachment (Mathieu and Zajac 1990), engagement (Christian et al. 2011) and reduction of fear (Cottrell 1972). If one were to analyze which organization designs would trigger which type of mechanism, one would find that they play out quite differently depending on where managers grant autonomy to their employees along the $4+1$ dimensions of organizing, though (Reitzig 2022, ch. 3). To foster self-actualization and perceived control, for example, it seems necessary to let people pick their own tasks. To foster attachment, permitting decentralized information exchange would appear sufficient. As such, design choices must be taken carefully to instill the motivation that managers would like their employees to feel eventually.

Part of this rationale should focus on the employees' personalities. Not all characters flourish equally well in the same decentralized structure, as not all of them are equally susceptible to being motivated to follow their own desires or being in charge of their work life, etc. Furthermore, employees may differ with regards to their willingness to engage in self-organization with others, they may be heterogenous 
when it comes to their cognitive abilities to work in a high delegation regime.

What research has shown, therefore, is that getting a workforce with a right mix of personality traits can help tremendously with operating a high delegation regime.

Employees who score high on traits such as need for achievement, conscientiousness (Barrick and Mount 1993), locus of control ( $\mathrm{Ng}$ et al. 2006), and proactiveness (Shin and Jeung 2019) should be the ones who thrive the most in the high delegation environment. It also takes people who are agreeable, polite, honest and humble to ensure that tedious tasks that come with self-organization are being attended to and that the decentral workplace is being maintained (Zhao et al. 2016). Finally, depending on where people are given the autonomy to carry out their work, there may be substantial demands on their cognitive abilities. This may be less the case when employees are merely left the chance to decide how they want to communicate with one another. It may be critical in instances when task division and task allocation are left to subordinates; which may be one of the reasons for why we often see more delegation of decision rights within those parts of the organization, where highly educated people work than in others.

But even when company leaders manage to assemble such a mix of personalities in their workforce, the success of a flat structure is not yet a given. It is important to treat these people correctly and provide them with a working environment that facilitates the self-organization.

\section{Which boundary conditions to set for effective and efficient self-organization?}

Selecting individuals who rank high on the above traits and who have been exposed to norms such as fairness and reciprocity undoubtedly helps the organization to do well without direct managerial control in many domains. Yet, even then, so research would suggest, implementing rules to sanction norm deviation by employees who are less susceptible to teamwork may be desirable (Yamagishi 1986; Chen et al. 2009). Many successful companies do so, at least in soft ways, by having team members have a great say in individual compensation of others. In addition, empowering employees, and providing them with what they need to conduct their autonomous work, becomes a key managerial task. A trust-engendering humble leadership style seems to be key in this regard (Cho et al., 2021). ${ }^{2}$

\footnotetext{
${ }^{2}$ Which additional behaviors or personality traits on the part of the managers might help with coordinating a flat structure continues to be an interesting open-ended research question. Some work suggests that dominant personalities might appreciate dealing with wider spans of control (Schumacher et al., 2016), however, the question is whether they would do so for the right reason.
}

But to make the flat structure not only effective but truly efficient it takes more than systems that prevent the flat structure from collapsing. The challenge for organizational designers is to create a playfield in which the cost of self-coordination is reduced as much as possible. Depending on where management seeks to delegate decision rights eventually, different design measures can become crucial. Modularization will facilitate high delegation pertaining to task division and allocation, and aid in avoiding excessive inter-team communication costs and duplication of effort (Baldwin and Clark 2000). Wikipedia provides an excellent case in point; the design is set up so that different groups of contributors can work on distinct articles (modules) without requiring to coordinate with one another intensively. Human resource slack will facilitate decentralized autonomous rewards distribution, without compromising on the reliability of the organization (Lecuona Torras and Reitzig 2014). Think of Patagonia: they let their people go surf when they want to, but they also employ more staff for the same work than their competitors would, thereby reducing the risk that clients will call them in vain at any given point in time. In addition, voting, lateral authority, and arbitration can enable efficient decentralized exception management-as MyFootballClub, Wikipedia, or Buurtzorg would demonstrate convincingly. At MyFootballClub fans can engage in voting on crucial decisions that might otherwise be contested. At Wikipedia, selected peers-i.e., administrators-serve as the last bastion to resolve conflicts peers might not be able to settle by themselves (Klapper and Reitzig 2018). Another example can be found at Buurtzorg, where coaches facilitate the discussion process among nurses when there is workrelated disagreement (Laloux 2014, p. 69). None of these approaches involve heavy handed managerial intervention of the traditional type.

Importantly, however, even the best workforce for a given flat structure, and even the most sophisticated way of treating them, may not create a flat advantage eventually, unless the structure is used to achieve goals that are commensurate with it.

\section{What (not) to use a flat structure for?}

Flat structures delegate more decision-making to their employees. Decision-making, however, entails three steps: (1) gathering information, (2) assessing it, and (3) acting upon it. The advantage of flat structures compared to their traditional counterparts can only unfold when, across the three stages, the benefit-to-cost ratio is superior in the high delegation regime. When is this the case? It would appear, as though three corporate goals were potentially better attained by flat structures than others: creativity, speed to market, and attraction/retention of personnel. 
Creativity benefits from the availability of diverse information to start with, as well as - up to a point - from the heterogeneity in viewpoints that are brought to its assessment and recombination. Highly interconnected flat structures can thus outperform minimum density networks-i.e., hierarchies_-in these regards. ${ }^{3}$ Not surprisingly are skunkworks, therefore, organized in a rather flat manner, and so are hackathons within corporations (see, e.g., Atlassian n.d.). Here, within a certain limited scope, employees can also realize their own ideas and feel in control of their fates. Thus, essentially, delegating task division and allocation, information exchange, and exception management thus seems ideal up to a point (Reitzig 2022, ch. 7). However, as the marginal returns to information gathering decrease with each new member to the team (Stasser and Titus 1985), and as communication costs non-linearly increase with each new person, it seems counterproductive to scale teams-based work beyond a certain threshold level. Where exactly that threshold level lies is a decision each organization has to make on its own. However, when the goal is fostering creativity, team sizes should be capped at some point and different groups ought to be re-embedded in a containment hierarchy, rather than to form one big discussion forum, when the corporation grows beyond a certain size. ${ }^{4}$ Another reason for not extending the flat structure beyond reason when seeking to boost creativity is its comparative disadvantage in acting upon information. Acting upon the creative output may be slowed down by a group consensus process compared to managerial selection. While this may pose little if any problems when it comes to small prototype development, the obstacles may painfully be felt when increasing the stakes. This is another reason for why using flat structures to foster creativity is often limited to prototype development and no longer prevails, when it comes to scaling costly businesses in successful organizations.

Similar, but distinctly different, considerations apply when seeking to increase speed to market through a flat structure. When speed hinges on finding scalable creative solutions to business problems, the above considerations can be mirrored one-to-one. When speed can be attained by creating small and affordable local solutions, however, the flat structure may extend across the entire organization, and

\footnotetext{
${ }^{3}$ For the potential flat structures have to enhance organizational creativity see Patanakul et al. 2012; Damanpour 1991; on the risk of fostering mental convergence when allowing for too much information exchange within groups see Shore et al. 2015.

${ }^{4}$ It is important to appreciate that teams-based work may prevail in parts of the organization but need not necessarily be the default mode across the entire organization. Flat subparts within the organization may, at times, become the building blocks of larger containment hierarchies.
}

employees may, in addition to the above autonomies, also be given the rights to split up their own performance bonuses.

Finally, when the goal is to attract and retain the right talent by adopting a flat structure, managers have a choice. Depending on whether they merely want to foster attachment, they may focus on delegating decision rights in how employees communicate with one another and about what. To the extent that leadership seeks to instill a sense of selfactualization and perceived control, they can also do so, but they must be careful in designing a playfield (see above) that is commensurate with such autonomy.

\section{Summary}

Creating a flat structure is no end it itself for a designer. Flat structures can (!) beat traditional hierarchies when the organizational goal is to become more creative, speedier, or attractive to human talent. It should also be kept in mind that flat structures can come in many different shapes. Between the two extremes of organizations that are either centralized or decentralized along all of the $4(+1)$ fundamental dimensions of organizing, a plethora of hybrids exist. There is no need to adopt any one of the off-the-shelves approaches, be it RenDanHeYi, Scrum, or any other, wholesale. There is no point in subscribing to approaches that replace one type of hierarchy with another, such as holacracy (Robertson 2015, p. 47), when the goal is to become flatter. Rather, when custom-tailoring flat structures to their needs, managers may wish to go back to first principles and rely on the empirical evidence scholarship has created over the past decades. Synthesizing these insights, it would appear as though succeeding with flat corporate structures requires preventing three design mismatches: mismatches (1) between the corporate goal and the flat structure, (2) between the flat structure and the staff inside the organization, and (3) between the flat structure and the way staff is being treated. Thinking through the questions raised in this article when devising a design should help.

Acknowledgements This article provides a brief synopsis of the ideas that are described in more detail in the homonymous book "Get better at flatter-a guide to shaping and leading organizations with less hierarchy" (Palgrave Macmillan: London, 2022).

Author contribution The author read and approved the final manuscript.

Funding Open access funding provided by University of Vienna.

Availability of data and materials Material draws in part on my own homonymous book, forthcoming with Springer Nature in 2022, entitled "Get better at flatter-shaping and leading organizations with less hierarchy". The forthcoming book is appropriately cited. 


\section{Declarations}

Competing interests The authors declare that they have no competing interests.

Open Access This article is licensed under a Creative Commons Attribution 4.0 International License, which permits use, sharing, adaptation, distribution and reproduction in any medium or format, as long as you give appropriate credit to the original author(s) and the source, provide a link to the Creative Commons licence, and indicate if changes were made. The images or other third party material in this article are included in the article's Creative Commons licence, unless indicated otherwise in a credit line to the material. If material is not included in the article's Creative Commons licence and your intended use is not permitted by statutory regulation or exceeds the permitted use, you will need to obtain permission directly from the copyright holder. To view a copy of this licence, visit http://creativecommons.org/licenses/by/4.0/.

\section{References}

Atlassian (n.d.) ShipIt. https://www.atlassian.com/company/shipit. Accessed 25 Feb 2021.

Baldwin C, Clark K (2000) Design rules: the power of modularity. MIT Press, Boston

Barrick MR, Mount MK (1993) Autonomy as a moderator of the relationships between the big five personality dimensions and job performance. J Appl Psychol 78(1):111-118

Burkus D (2016) why atos origin is striving to be a zero-email company. Forbes. https://www.forbes.com/sites/davidburkus/2016/07/ 12/why-atos-origin-is-striving-to-be-a-zero-email-company/?sh= 240b04368d0f. Accessed 22 Feb 2021.

Chen XP, Pillutla MM, Yao X (2009) Unintended consequences of cooperation inducing and maintaining mechanisms in public goods dilemmas: sanctions and moral appeals. Group Process Intergroup Relat 12(2):241-255

Cho J, Schilpzand P, Huang L, Paterson T (2021) How and when humble leadership facilitates employee job performance: the roles of feeling trusted and job autonomy. J Leadersh Organ Stud. https:// doi.org/10.1177/1548051820979634

Chouinard Y (2016) Let my people go surfing. Penguin Books, New York

Christian MS, Garza AS, Slaughter JE (2011) Work engagement: a quantitative review and test of its relations with task and contextual performance. Pers Psychol 64(1):89-136

Cottrell NB (1972) Social Facilitation. In: McClintock C (ed) Experimental social psychology. Holt Rinehart and Winston, New York, pp 185-236

Damanpour F (1991) Organizational innovation: a meta-analysis of effects of determinants and moderators. Acad Manag J 34(3):555-590

Hackman JR, Oldham GR (1976) Motivation through the design of work: test of a theory. Organ Behav Hum Perform 16(2):250-279

Hofmann DA, Morgeson F, Gerras S (2003) Climate as a moderator of the relationship between LMX and content specific citizenship: safety climate as an exemplar. J Appl Psychol 88:170-178

Ivancevich JM, Donnelly JH (1975) Relation of organizational structure to job satisfaction, anxiety-stress, and performance. Adm Sci Q 20(2):272-280

Kelly T. (n.d.) The End of Hierarchy: Natural Leadership at W.L. Gore. Management Innovation eXchange. https://www.management exchange.com/video/terri-kelly-wl-gores-original-managementmodel-0. Accessed 22 Feb 2021.
Klapper H, Reitzig M (2018) On the effects of authority on peer motivation: learning from wikipedia. Strateg Manag J 39(8):2178-2203

Laloux F (2014) Reinventing organizations: a guide to creating organizations inspired by the next stage of human consciousness. Nelson Parker, Brussels, p 69

Lecuona Torras R, Reitzig M (2014) Knowledge worth having in 'excess': the value of tacit and firm-specific human resource slack. Strateg Manag J 35(7):954-973

Mathieu JE, Zajac DM (1990) A review and meta-analysis of the antecedents, correlates, and consequences of organizational commitment. Psychol Bull 108(2):171-194

Morrison EW (1994) Role definitions and organizational citizenship behavior: the importance of the employee's perspective. Acad Manag J 37:1543-1567

Ng TWH, Sorensen KI, Eby LT (2006) Locus of control at work: a meta-analysis. J Organ Behav 27:1057-1087

Oettl CA, Beck K, Raufer FM, Priglmeir AT, Böhm M, Krcmar H (2018) Zero Email initiative: a critical review of change management during the introduction of enterprise social networks. J Technol Teach Cases 8:172-183. https://doi.org/10.1057/ s41266-018-0033-y

Patanakul P, Chen J, Lynn GS (2012) Autonomous teams and new product development. J Prod Innov Manag 29(5):734-750

Puranam P, Alexy O, Reitzig M (2014) What's 'New' about new forms of organizing? Acad Manag Rev 39(2):162-180

Rajan RG, Wulf J (2006) The flattening firm: evidence from panel data on the changing nature of corporate hierarchies. Rev Econ Stat 88(4):759-773

Reitzig M (2022) Get better at flatter-a guide to shaping and leading organizations with less hierarchy. Palgrave Macmillan, London

Robertson BJ (2015) Holacracy: the new management system for a rapidly changing world. Henry Holt and Company, New York

Ryan RM, Deci EL (2000) Self-determination theory and the facilitation of intrinsic motivation, social development, and well-being. Am Psychol 55(1):68-78

Schumacher C, Keck S, Reitzig, M. (2016). Organizational Structure and CEO Dominance. Academy of Management Conference Best Paper Proceedings, https://doi.org/10.5465/ambpp.2016.13612 abstract

Shin I, Jeung C (2019) Uncovering the turnover intention of proactive employees: the mediating role of work engagement and the moderated mediating role of job autonomy. IJERPH 16(5):843

Shore J, Bernstein E, Lazer D (2015) Facts and figuring: an experimental investigation of network structure and performance in information and solution spaces. Organ Sci 26(5):1432-1446

Smarkets (2016) Setting your own salary. https://www.youtube.com/ watch?v=zwFMMJpTfbM. Accessed 17 Feb 2021.

Smeets V, Warzynski F (2008) Too many theories, too few facts? What the data tell us about the link between span of control compensation and career dynamics. Labour Econ 15(4):687-703

Spector PE (1986) Perceived control by employees: a meta-analysis of studies concerning autonomy and participation at work. Human Relations 39:1005-1016

Stasser G, Titus W (1985) Pooling of unshared information in group decision-making - biased information sampling during discussion. J Pers Soc Psychol 48(6):1467-1478

US Census Bureau (2021) 2017 SUSB Annual Data Tables by Establishment Industry. https://www.census.gov/data/tables/2017/econ/ susb/2017-susb-annual.html. Accessed 14 Oct 2021.

Valve (2012) Valve Handbook for New Employees. https://assets.sbnat ion.com/assets/1074301/Valve_Handbook_LowRes.pdf. Accessed 27 Feb 2021.

Yamagishi T (1986) The provision of a sanctioning system as a public good. J Pers Soc Psychol 51(1):110-116

Zhao K, Ferguson E, Smillie LD (2016) Prosocial personality traits differentially predict egalitarianism, generosity, and reciprocity 
in economic games. Front Psychol. https://doi.org/10.3389/fpsyg. 2016.01137

Publisher's Note Springer Nature remains neutral with regard to jurisdictional claims in published maps and institutional affiliations. 